\title{
EFECTUL UTILIZĂRII ELEMENTELOR NUTRITIVE PENTRU GERMINARE ȘI CREȘTERE ASUPRA INDICILOR FOTOSINTETICI AI FRUNZELOR DE PORUMB Zea mays L.
}

\author{
Cauș Maria ${ }^{1}$, Dascaliuc Alexandru ${ }^{1}$, Borozan Pantelimon ${ }^{2}$ Eichler-Lobermann Bettina ${ }^{3}$ \\ ${ }^{1}$ Institutul de Genetică, Fiziologie şi Protecţie a Plantelor, Chișinău, Republica Moldova, ${ }^{2}$ Institutul de \\ Fitotehnie „Porumbeni”, Pașcani, Republica Moldova, \\ ${ }^{3}$ Universitatea din Rostock, Germania, e-mail: maria.caus@igfpp.md \\ Abstract
}

In this study experiments were conducted on the influence of $1 / 2$ Hoagland nutrient media (NM), utilized for germination, on the content of chlorophylls, carotenoids and activity of photosystem II (FSII) of two maize hybrids (Porumbeni 180 and Bemo 203). The results showed that contents of chlorophyll a, b, $(a+b)$ and carotenoids were significantly higher in leaves of Bemo 203 that germinated on NM, compared to the control. But in leaves of the Porumbeni 180 hybrid significant differences in the content of chlorophyll pigments in both the control and experimental plants were not detected. The FSII level in the leaves of the Porumbeni 180 was higher than in leaves of the Bemo 203, both for the control and experimental plants.

Key words: Maize hybrids, 1/2 Hoagland nutrient media, photosynthetic indices

\section{Introducere}

Ciclul de viață al plantelor include mai multe faze de dezvoltare, inclusiv fazele incipiente ale ontogenezei. Schimbările morfo - fiziologice care apar în fazele iniţiale de îmbibare a semințelor, germinare, apariție și formare a răsadurilor sunt de-o importanță decisivă pentru dezvoltarea în continuare a plantelor. Creșterea și dezvoltarea plantelor este influențată de un șir de factori ai mediului ambiant, inclusiv abiotici, biotici, precum și asigurarea cu elemente nutritive.

Porumbul (Zea mays L.), este o cultură cu cerințe nutritive ridicate, care necesită aprovizionarea adecvată cu nutrienții esențiali ai plantelor [7]. În rapoartele recente se aduc date despre sensibilitatea porumbului la deficiența de macro - $[1,5,10,13]$ și microelemente $[6,11]$. Insuficiența unor elemente nutritive esențiale în mediu de creștere provoacă diverse dereglări în desfășurarea metabolismului vegetal $[1,9]$.

Pentru depășirea efectelor negative ale mediului de nutriție asupra obținerii unor răsaduri sănătoase şi viguroase sunt antrenate diferite strategii și tehnici de fertilizare a culturilor agricole, inclusiv amorsarea semințelor cu soluții nutritive $[2,6,12]$.

Rapoartele anterioare [8,9] au identificat impactul insuficienței a unor elemente nutritive în sol asupra metabolismului altor elemente minerale, schimbând asimilarea, utilizarea și distribuirea nutrienților respectivi între organele vegetale.

Pentru evaluarea impactului relativ al stresurilor de mediu, inclusiv celui nutritiv asupra creșterii și dezvoltării plantelor sunt utilizaţi un şir de parametri fiziologici, inclusiv conținutul pigmenţilor clorofilieni, carotinoidelor, precum și activitatea fotosistemei II (cuantum yield FS II) [9, 10, 14].

Scopul acestui studiu a constat în determinarea efectului utilizării soluției de nutrienți pentru germinare și crește a plantelor de porumb asupra indicilor fotosintetici ai frunzelor de porumb.

\section{Materiale şi metode}

Ca obiect de studiu au servit plantele de Zea mays L., crescute din semințe a hibrizilor de porumb Porumbeni 180 și Bemo 203, selectate în Instituţia Publică Institutul de Fitotehnie „Porumbeni”. Cercetările experimentale s-au desfășurat în condiții controlate de laborator, la $25^{\circ} \mathrm{C}$. Înainte de germinare semințele au fost îmbibate în apă distilată timp de 36 ore la $5^{\circ} \mathrm{C}$. Ulterior, semințele îmbibate au fost plasate în termostat la $25^{\circ} \mathrm{C}$, la întuneric și umiditatea aerului de $60-70 \%$. Germinația semințelor s-a efectuat pe apă distilată (martor) sau pe 1/2 soluție nutritivă Hoagland (3). După 5 zile germenii martor și experimentali au fost transferați la lumină, cu utilizarea a două tipuri de lămpi Led pentru iluminare, inclusiv 395 $400 \mathrm{~nm}$ și $650-680 \mathrm{~nm}$, FAR de $150 \mu \mathrm{mol} \times \mathrm{m}-2 \times$ sec- 1 și o fotoperioadă de 16 ore - lumină, 8 ore întuneric. Creșterea plantulelor la lumină s-a efectuat cu utilizarea culturii pe apă și $1 / 2$ soluției nutritive 
Hoagland, atât pentru plantele martor, cât și experimentale. Frunzele au fost selectate de la plantele de porumb cu vârsta de 17 zile.

Conținutul clorofilei $a, b$ și a carotenoidelor a fost determinat spectrofotometric prin măsurarea densităţii optice a extractului de pigmenţi la lungimi de undă $662 \mathrm{~nm}, 644 \mathrm{~nm}$ și 440,5 nm, urmată de calcularea concentrației de pigmenți conform ecuațiilor Wetstein și Holm $(4,13)$. Absorbția extractelor a fost măsurată cu utilizarea spectrofotometrului UV-Vis Agilent 8453. Conţinutul de pigmenți fotosintetici a fost exprimat în $\mathrm{mg} \cdot \mathrm{g}^{-1}$ masă proaspătă.

Măsurarea activității fotosistemei II a frunzelor de porumb (indicele Yield) a fost determinată folosind fluorimetru portabil PAM-2100 (Walz, Germania).

\section{Rezultate şi discuţii}

Determinările conținutului de pigmenți clorofilieni și carotinoide în frunzele de porumb în dependenţă de mediu de germinare sunt prezentate în figura 1. Putem observa că mediu nutritiv utilizat pentru germinare și creștere a modificat în mod deosebit conținutul de clorofilă și carotenoide în frunzele plantelor hibridului Bemo 203. Conţinutul clorofilei $a, b$ și a carotinoidelor în varianta cu utilizarea mediului nutritiv pentru germinare este semnificativ mai mare decât în varianta martor $(\mathrm{H} 2 \mathrm{O})$. În același timp în frunzele hibridului Porumbeni 180 deosebiri semnificative în conţinutul pigmenților clorofilieni și carotinoide în dependență de utilizarea mediului nutritiv pentru germinare nu au fost identificate (Fig. 1). Tot odată, putem observa, că nivelul sumar al conținutului pigmenților și carotinoidelor în frunzele hibridului Porumbeni 180 este mai mare decât în frunzele hibridului Bemo 203 (Fig.1).

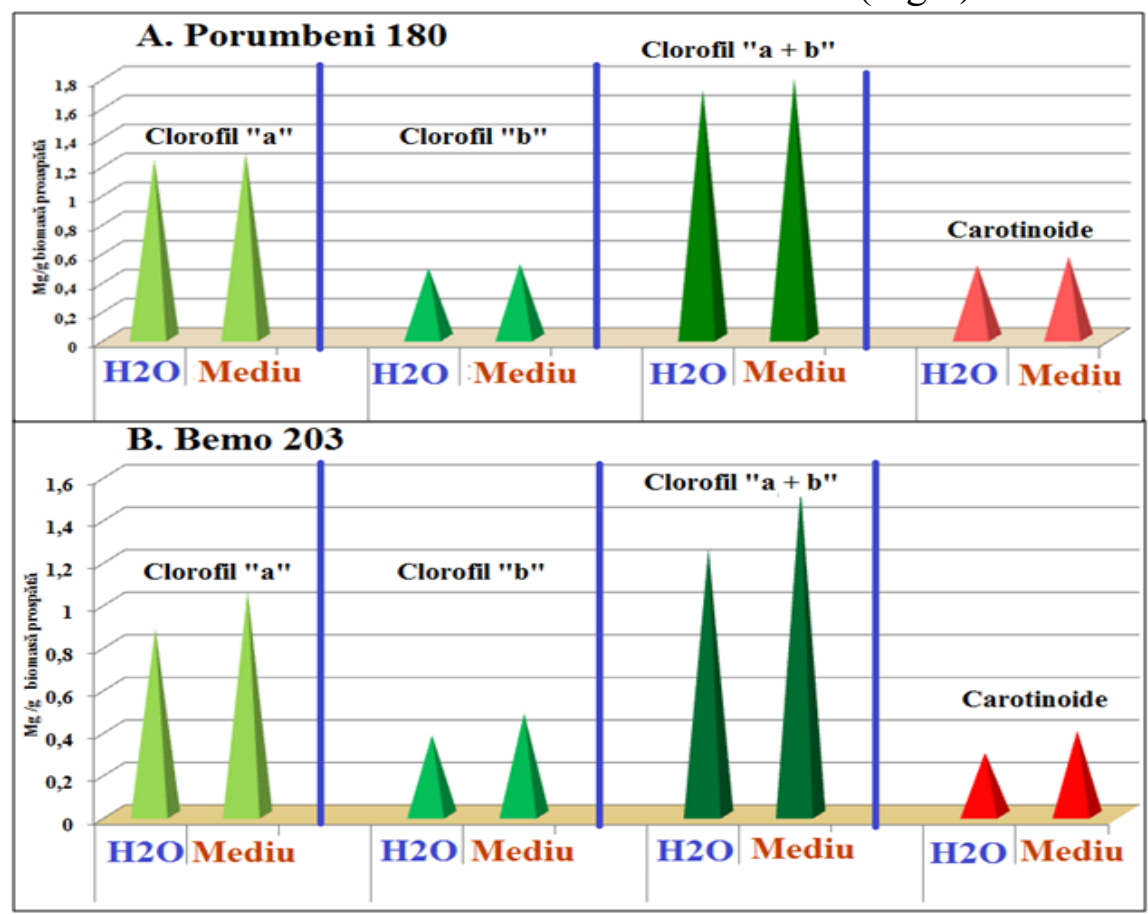

Fig.1. Rezultatele măsurării conținutului pigmenților clorofilieni și a carotinoidelor în frunzele de porumb, crescut din semințe ce au germinat în decurs de 5 zile pe apă distilată (martor) sau pe mediu nutritiv (experiment) la întuneric, cu creșterea ulterioară la lumină până la vârsta de 17 zile.

Determinarea raportului dintre clorofila $a$ / $b$ (Fig.2), de asemenea, a demonstrat că valorile acestui indice sunt mai mari pentru hibridul Porumbeni 180, comparativ cu hibridul Bemo 203. Deși, după cum se vede din figura 2 raportul dintre clorofila $a$ / $b$ pentru Bemo 203 în varianta martor (H2O) este mai mare, decât în varianta cu mediu nutritiv. Aceste rezultate demonstrează că utilizarea mediului nutritiv pentru germinare sporește producerea clorofile $b$.

Creșterea raportului carotenoide / clorofila $(a+b)$ la frunzele plantelor ambelor hibrizi, dar de menționat, că pentru hibridul Bemo 203 acest parametru este la un nivel mai mare, comparativ cu cel pentru Porumbeni 180 (Fig. 2B). Aceste rezultate sugerează, că starea fiziologică a plantelor, obținute din semințe ce au germinat pe mediu nutritiv sunt la un nivel mai satisfăcător, manifestând o vigurozitate mai sporită. 


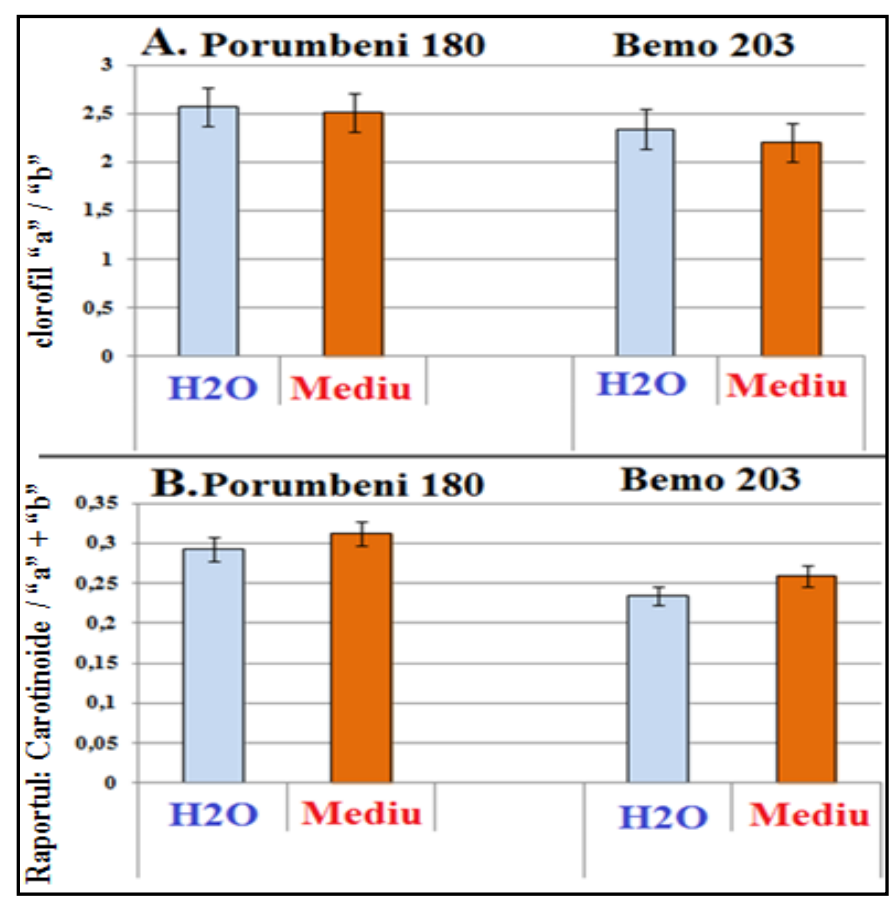

Fig. 2. Modificări ale raportului clorofila $a / b(\mathrm{~A})$ și raportului carotenoidelor / clorofila $(\mathrm{a}+\mathrm{b})(\mathrm{B})$ în frunzele plantelor de porumb ale hibridului Porumbeni 180 și Bemo 203 ce au crescut din semințe care au germinat în decurs de 5 zile pe apă distilată (martor) sau pe mediu nutritiv (experiment) la întuneric, cu creșterea ulterioară la lumină până la vârsta de 17 zile.

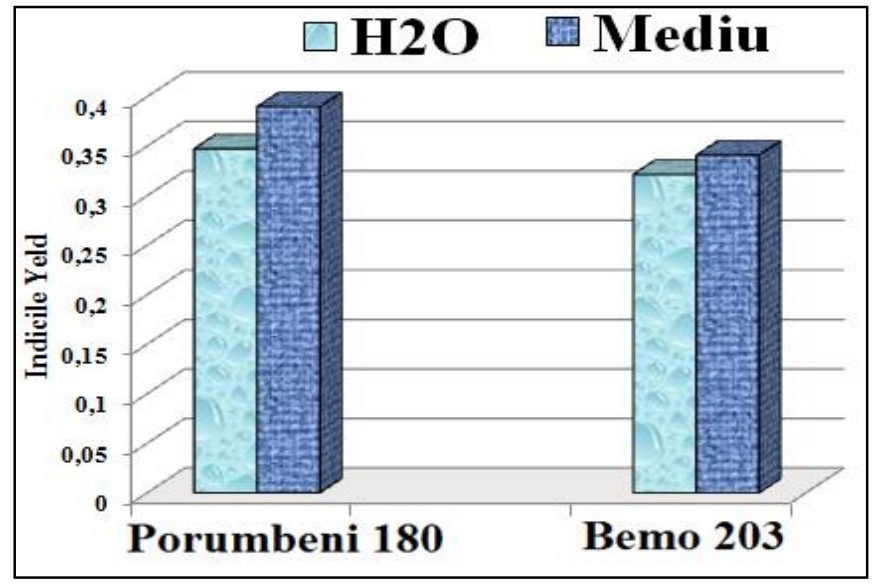

Fig. 3. Eficiența fotosintetică (EF) a frunzelor de porumb hibrizilor Porumbeni 180 și Bemo 203, produse din semințe ce au germinat pe apă (martor) sau pe mediu nutritiv (experiment) la întuneric, cu creșterea ulterioară la lumină până la vârsta de 17 zile.

Comparativ cu conținutul pigmenților clorofilieni indicele yield al FSII, de asemenea, a fost la un nivel mai înalt în variantele experimentale la ambii hibrizi. Deși, după cum arată datele prezentate în Figura 3, nivelul FSII în frunzele hibridului Porumbeni 180 este mai mare decât în frunzele hibridului Bemo203, atât pentru plantele obținute din semințe ce au germinat pe apă (martor), cât și pentru cele experimentale, ce au germinat pe mediu nutritiv. Nivelul semnificativ mai jos al PSII pentru frunzele plantelor obținute din semințe ce au germinat pe apă, probabil, că este asociată cu asimilarea redusă a $\mathrm{CO}_{2}$ și diminuarea activității fotosistemelor (9). Plantele crescute în condiții cu insuficiență de nutrienți în mediu de creștere au manifestat o diminuare a asimilării CO2, însoțită de disiparea excesului de energiei pentru o performanță optimă a fotosistemelor și pentru a se evita fotoinhibiția (9).

Rezultatele obținute în lucrarea noastră sugerează, că aplicarea mediului nutritiv pentru germinare favorizează activitatea componentelor aparatului fotosintetic în convertirea energiei luminii de către frunzele ambelor hibrizi studiați. Astfel, randamentul cuantic al FS II și conținutul pigmenților clorofilieni al frunzelor de porumb variază în funcție de mediu nutritiv utilizat pentru germinare.

\section{Concluzii}

1. Aplicarea $1 / 2$ soluției nutritive Hoagland pentru germinarea semințelor de porumb a hibrizilor Porumbeni 180 și Bemo 203 a condiţionat majorarea conținutului de clorofilă, carotinoide și randamentul cuantic al FSII în faza timpurie de creștere a plantelor.

2. Efectul aplicării mediului nutritiv pentru germinarea semințelor asupra conținutului pigmenților clorofilieni în frunzele hibridului Bemo 203 a fost mai accentuat, comparativ cu hibridul Porumbeni 180.

Cercetările au fost realizate în cadrul proiectului Programului de Stat 20.80009.7007.07 „Determinarea parametrilor ce caracterizează rezistența plantelor cu nivel diferit de organizare la acțiunea temperaturilor extreme în scopul diminuării efectelor schimbărilor climatice”, finanțat de Agenția Națională pentru Cercetare și Dezvoltare. 


\section{Bibliografie}

1. DU, QI., ZHAO, XIN-HUA1, XIA, LE et al. Effects of potassium deficiency on photosynthesis, chloroplast ultrastructure, ROS, and antioxidant activities in maize (Zea mays L.)// J. Integrative Agriculture, 2019, vol. 18(2), p.395-406.

2. FAROOQ, M., WAHID, A., SIDDIQUE, K.H.M. Micronutrient application through seed treatments - a review.// J.Soil Sci. \&Plant Nutr., 2012, 12 (1), p. 125-142.

3. HOAGLAND, D . R., ARNON, D. The water culture method for growing plants without soil. California Agricultural Experimental Station Circular, 1950, No. 347, p. 1-32. University of California, Berkeley.

4. HOLM G. Chlorophyll mutations in barley // Acta. Agr. Scand. 1954. V. 4. P. 457-471.

5. JEZEK, M., GEILFUS, C.M., BAYER, A., MÜHLING, K.H. Photosynthetic capacity, nutrient status, and growth of maize (Zea mays L.) upon MgSO4 leaf-application. // Front.Plant Sci.Crop Sci. Horticulture, 2015, vol. 15. Article 781. 10 p. doi: 10.3389/fpls.2014.00781

6. NCIIZAH, A.D., RAPETSOA, M.C., WAKINDIKI, I.I.C., ZERIZGHY M. G. Micronutrient seed priming improves maize (Zea mays) early seedling growth in a micronutrient deficient soil. // Heliyon 2020, vol. 6. e04766. https://doi.org/10.1016/j.heliyon.2020.e04766

7. PRISECARU, G., SALA, F. Response model of vegetation parameters and yield in maize under the influence of Lithovit fertilizer.// Intern. Confer. Numerical Analysis and Applied Mathemat., AIP Conf. Proceed., 2017, 1863, 430005-1-430005-4; doi: 10.1063/1.4992601

8. RUFTY, T.W., SIDDIQI, M.Y., GLASS, A.D.M., RUTH, T.J. Altered ${ }^{13} \mathrm{NO}_{3}-$ influx in phosphorus limited plants. // Plant Sci., 1991, vol. 76, p. 43- 48,

9. SINGH, S.K., REDDY, V.R., FLEISHE,R D.H., TIMLIN, D.J. Relationship between photosynthetic pigments and chlorophyll fluorescence in soybean under varying phosphorus nutrition at ambient and elevated $\mathrm{CO}_{2}$. // Photosynthetica, 2017, vol. 55 (3), p. 421-433.

10. SITKO, K., GIEROŃ, Ż., SZOPIŃSKI, M. et al. Influence of short-term macronutrient deprivation in maize on photosynthetic characteristics, transpiration and pigment content. // Sci. Reports, 2019, vol. 9, 14181. https://doi.org/10.1038/s41598-019-50579-1

11. SUGANYA, A., SARAVANAN, A., MANIVANNAN, N. Role of zinc nutrition for increasing zinc availability, uptake, yield, and quality of maize (Zea mays L.) Grains: An overview. communication. // Soil Sci. Plant. Anal. 2020, 51 (15), p. 2001-2021.

12. TONDEY, M., KALIA, A., SINGH, A. et al. Seed priming and coating by nano-scale zinc oxide particles improved vegetative growth, yield and quality of fodder maize (Zea mays). // Agronomy 2021, 11, 729. https://doi.org/10.3390/agronomy11040729.

13. WETTSTEIN, D. Chlorophyll letale und der submikroskopische Formwechsel der Plastiden // Exp. Cell Res. 1957. V. 12. P. 427-434.

14. WU, Y. W., LI, Q., , Jin R. et al. Effect of low-nitrogen stress on photosynthesis and chlorophyll fluorescence characteristics of maize cultivars with different low nitrogen tolerances.// J. Integrative Agriculture, 2019, vol. 18(6), p. 1246-1256. 